CONGENITAL HEART DISEASE

\title{
Echocardiographic predictors of adverse clinical events in children with dilated cardiomyopathy: a prospective clinical study
}

\author{
C J McMahon, S F Nagueh, R S Eapen, W J Dreyer, I Finkelshtyn, X Cao, B W Eidem, L I Bezold, \\ S W Denfield, J A Towbin, R H Pignatelli
}

Heart 2004;90:908-915. doi: 10.1136/hrt.2003.020966

See end of article for authors' affiliations

.....................

Correspondence to: Dr C J McMahon, Lillie Frank Abercrombie Division of Pediatric Cardiology, Texas Children's Hospital, 6621 Fannin, Houston, Texas 77030, USA: cmcmahon@bcm.tmc.edu

Accepted 16 October 2003
Objectives: To compare tissue Doppler (TD) velocities between patients with dilated cardiomyopathy (DCM) and normal controls and to determine whether TD velocities, Tei index, right ventricular fractional area change, and left ventricular ejection fraction (LVEF) predict adverse clinical outcomes in children with DCM.

Methods: Prospective evaluation of children with DCM.

Results: 54 children with DCM and 54 age and sex matched control group participants were studied. Mitral inflow velocities were similar for both groups except for decreased mitral deceleration time in patients with DCM. Systolic and diastolic TD velocities at the mitral annulus (septal and lateral sides) and tricuspid annulus were significantly reduced in children with DCM compared with controls $(p<0.001$ for each). By multivariate analysis, after adjustment for Tei index and right ventricular fractional area change, decreased LVEF and tricuspid velocity during early diastole $(E a)$ were predictors of the primary end point (PEP), a composite end point consisting of need for hospitalisation or the outcome transplantation or death. Tricuspid Ea velocity $<8.5 \mathrm{~cm} / \mathrm{s}$ had $87 \%$ specificity and $60 \%$ sensitivity for reaching the PEP. LVEF $<30 \%$ had $68 \%$ specificity and $74 \%$ sensitivity for the PEP. Combined LVEF $<30 \%$ and tricuspid Ea $<11.5 \mathrm{~cm} / \mathrm{s}$ had $100 \%$ specificity and $44 \%$ sensitivity for the PEP.

Conclusions: Children with DCM have significantly lower TD velocities than normal controls. In such cases, lower LVEF $(<30 \%)$ is more sensitive but less specific than lower tricuspid Ea velocities $(<8.5 \mathrm{~cm} / \mathrm{s})$ in predicting which patients are at risk of hospitalisation, transplantation, or death.
$\mathrm{P}$ redictors of adverse clinical outcomes in children with dilated cardiomyopathy (DCM) remain limited despite several studies over the past two decades. ${ }^{1-5}$ Recent success with ventricular assist devices and cardiac transplantation, the limited numbers of donors for transplantation, and the morbidity and mortality during the waiting period for transplantation make it important for the clinician to develop an accurate means of risk stratification of children presenting with DCM.

Adult studies have shown that newer echocardiographically derived indices of systolic and diastolic function are clinically relevant among patients with several myocardial disorders. ${ }^{6-13}$ Tissue Doppler (TD) velocities measure myocardial and annular velocities during systole (Sa), early diastole (Ea), and late diastole (Aa) and have been shown to be preload independent indices of diastolic ventricular function. ${ }^{14}$ In addition to quantifying myocardial systolic and diastolic function, TD has been shown to predict ventricular end diastolic pressures and identify underlying gene mutations responsible for hypertrophic cardiomyopathy in adults. ${ }^{14-19}$

TD velocities have become a standard part of echocardiographic evaluation in several institutions because these velocities are readily acquired and highly reproducible. ${ }^{14161720}$ Although TD velocities in normal children, cancer survivors, and patients after tetralogy of Fallot repair have been studied, the use of TD as a prognostic factor in determining prognosis in children with DCM is unknown. ${ }^{20-22}$ Our purpose, therefore, was to assess the clinical utility of traditional echocardiographic measurements compared with TD velocities as discriminators between patients with DCM and a group of control participants, and to determine whether TD velocities can prospectively predict adverse clinical outcomes in children with DCM.

\section{METHODS}

We prospectively studied paediatric patients with DCM who presented to the Texas Children's Hospital between January 1999 and June 2002. DCM was defined as a left ventricular ejection fraction (LVEF) $<40 \%$ with left ventricular end diastolic dimension (LVEDD) $>2$ z scores. During the study period, DCM was diagnosed or being followed up in 70 patients. Sixteen patients were excluded from the study cohort because of poor echocardiographic windows, suboptimal TD imaging, or incomplete acquisition of study data. Excluded patients were of similar age and sex and had similar two dimensional echocardiographic parameters as patients who were enrolled. No patients had underlying congenital heart defects. Standard echocardiography was performed with pulse wave Doppler to record mitral and tricuspid inflow patterns at the leaflet tips in the apical four chamber view. ${ }^{16}$ TD imaging was applied in the pulse Doppler mode to enable spectral display at the lateral mitral and septal annuli and at the tricuspid lateral wall adjacent to the

Abbreviations: Aa, late diastole; DCM, dilated cardiomyopathy; Ea, early diastole; LVEDD, left ventricular end diastolic dimension; LVEF, left ventricular ejection fraction; NYHA, New York Heart Association; PEP, primary end point; RVFAC, right ventricular fractional area change; Sa, systole; TD, tissue Doppler 
atrioventricular valve hinge points. ${ }^{16}$ Filters and gains were adjusted to allow a clear tissue signal and to minimise background noise.

\section{Echocardiographic analysis}

A single observer, blinded to the clinical status of patients, analysed the images off line. Two dimensional measurements were LVEDD, left ventricular end systolic dimension, and left ventricular posterior wall thickness. LVEF was measured with Simpson's biplane method in the latter. ${ }^{23}$ Mitral inflow was analysed for peak E and A wave velocities, acceleration and deceleration times of the E wave velocity, and isovolumetric contraction and relaxation times. ${ }^{14}$ The tricuspid regurgitation jet velocity (in $\mathrm{m} / \mathrm{s}$ ) was measured when possible. The right ventricular fractional area change (RVFAC) was measured from the apical four chamber and parasternal short axis views. ${ }^{24}$ The Tei index (left and right ventricles), which is the sum of isovolumetric contraction and relaxation times divided by the ventricular ejection time, was also measured in standard fashion. ${ }^{25}{ }^{26} \mathrm{Sa}, \mathrm{Ea}$, and Aa TD velocities were measured at the mitral lateral, septal, and tricuspid lateral walls in accordance with previously published reports. ${ }^{142122}$

\section{Patient analysis}

Basic demographic data (age, sex, age at diagnosis, treatment) were collected. Echocardiograms were recorded the same day as the clinical examination to determine New York Heart Association (NYHA) classification. The primary end point (PEP) of the study was a composite end point of death, heart transplantation, and the need for hospitalisation. We assessed the use of intravenous inotropic support as a secondary end point.

\section{Statistical analysis}

Data are expressed as mean (SD) or median (25th to 75th centile) based on whether they have a normal distribution. Univariate and multivariate analyses with stepwise logistic regression were performed to determine predictors of outcome. A significance level of 0.05 was required for retention in the final multivariate model.

\section{RESULTS}

\section{Patient characteristics}

Fifty four patients with DCM were compared with 54 age and sex matched control group participants. The mean LVEF was $33 \%$ for DCM patients compared with 57\% for controls (table 1). The median age at diagnosis was 5 years (range $0.5-18$ years). The median duration of patient follow up was 21 months (range 6-42 months). Forty five patients were enrolled as outpatients or at the time of diagnosis and nine patients were enrolled after diagnosis and commencement of medicines during hospital admission. At the time of enrolment 41 patients were in NYHA class I-II and 13 in class III-IV. At termination of the study 32 patients were in NYHA class I-II and 22 in class III-IV. Thirty one patients were taking diuretics, 40 were taking angiotensin converting enzyme inhibitors, and 29 were taking cardiac glycosides. Twenty patients were treated with $\beta$ blockers during the study period. Thirty patients required hospitalisation for

Table 1 Tissue Doppler characteristics of 54 children with dilated cardiomyopathy (DCM) compared with an age and sex matched control group

\begin{tabular}{|c|c|c|c|}
\hline Variable & $\mathrm{DCM}(\mathrm{n}=54)$ & Control $(n=54)$ & p Value \\
\hline \multicolumn{4}{|l|}{ Demographics and vital signs } \\
\hline Male sex & $26(46 \%)$ & $34(52 \%)$ & 0.93 \\
\hline Age (years) & $3.0(1.3-13.7)$ & $5.5(2.0-8.1)$ & 0.78 \\
\hline Heart rate (beats/min) & $121(25)$ & $109(39)$ & 0.98 \\
\hline Blood pressure $(\mathrm{mm} \mathrm{Hg})$ & $87 / 31$ & $94 / 47$ & 0.87 \\
\hline \multicolumn{4}{|l|}{ Ventricular dimensions } \\
\hline LVEDD (mm) & $41.7(29.7-58)$ & $36.2(32.7-40.2)$ & $<0.001$ \\
\hline LVEDD z score & $2.51(2.00-3.61)$ & $-0.02(-1.03-1.03)$ & $<0.001$ \\
\hline IVS (mm) & $6.70(1.80)$ & $7.10(1.87)$ & 0.38 \\
\hline IVS z score & $0.36(1.03)$ & -0.03 (1.09) & 0.13 \\
\hline LVPW (mm) & $7.0(0.27)$ & $6.6(0.19)$ & 0.43 \\
\hline LVPW z score & $0.22(-0.75-2.22)$ & $-0.5(-1.13-0.76)$ & 0.02 \\
\hline \multicolumn{4}{|l|}{ Mitral inflow } \\
\hline Peak $A$ velocity $(\mathrm{cm} / \mathrm{s})$ & 50 (19) & $48(13)$ & 0.76 \\
\hline E wave $(\mathrm{cm} / \mathrm{s})$ & $83(17)$ & 89 (15) & 0.10 \\
\hline Acceleration time (ms) & 67 (17) & 76 (17) & 0.06 \\
\hline Deceleration time (ms) & $94(29)$ & $115(31)$ & 0.01 \\
\hline IVCT (ms) & $85(68-103)$ & $63(55-72)$ & $<0.001$ \\
\hline IVRT (ms) & $68(44)$ & 55 (27) & 0.05 \\
\hline \multicolumn{4}{|l|}{ Ventricular function } \\
\hline LV Tei index & $0.61(0.39-0.84)$ & $0.38(0.29-0.45)$ & 0.002 \\
\hline RV Tei index & $0.55(0.43-0.65)$ & $0.27(0.24-0.32)$ & $<0.001$ \\
\hline LVEF (\%) & $33(18-38)$ & $57(53-65)$ & $<0.001$ \\
\hline RVFAC (\%) & $31(27.5-40)$ & $61(57-65.5)$ & $<0.001$ \\
\hline \multicolumn{4}{|l|}{ TD measurements } \\
\hline Mitral lateral Ea $(\mathrm{cm} / \mathrm{s})$ & $11.7(4.3)$ & $16.5(4.1)$ & $<0.001$ \\
\hline Mitral lateral $\mathrm{Aa}(\mathrm{cm} / \mathrm{s})$ & $5.4(1.9)$ & $7.1(2.1)$ & $<0.001$ \\
\hline Mitral lateral Sa $(\mathrm{cm} / \mathrm{s})$ & $6.3(4.9-8.3)$ & $7.7(6.1-10.3)$ & $<0.001$ \\
\hline Mitral septal Ea $(\mathrm{cm} / \mathrm{s})$ & $7.9(6.3-10.3)$ & $13.7(11.2-16.0)$ & $<0.001$ \\
\hline Mitral septal Aa $(\mathrm{cm} / \mathrm{s})$ & $5.4(3.9-7.0)$ & $7.2(5.8-8.4)$ & $<0.001$ \\
\hline Mitral septal Sa $(\mathrm{cm} / \mathrm{s})$ & $5.4(4.3-7.1)$ & $7.7(6.2-10.3)$ & $<0.001$ \\
\hline Tricuspid lateral Ea $(\mathrm{cm} / \mathrm{s})$ & $12.3(4.1-14.8)$ & $16.2(13.6-17.8)$ & $<0.001$ \\
\hline Tricuspid lateral $\mathrm{Aa}(\mathrm{cm} / \mathrm{s})$ & $8.7(6.0-10.7)$ & $10.3(8.5-12.7)$ & $<0.001$ \\
\hline Tricuspid lateral $\mathrm{Sa}(\mathrm{cm} / \mathrm{s})$ & $11.0(8.5-12.9)$ & $11.9(9.3-13.4)$ & 0.15 \\
\hline
\end{tabular}

Data presented as median (25th-75th centile) or as mean (SD) where appropriate.

$\mathrm{Aa}$, late diastole; Ea, early diastole; IVCT, isovolumetric contraction time; IVRT, isovolumetric relaxation time; IVS interventricular septum; LV, left ventricle; LVEDD, left ventricular end diastolic dimension; LVEF, left ventricular ejection fraction; LVPW, left ventricular posterior wall; RV, right ventricle; RVFAC, right ventricular fractional area change; Sa, systole. 

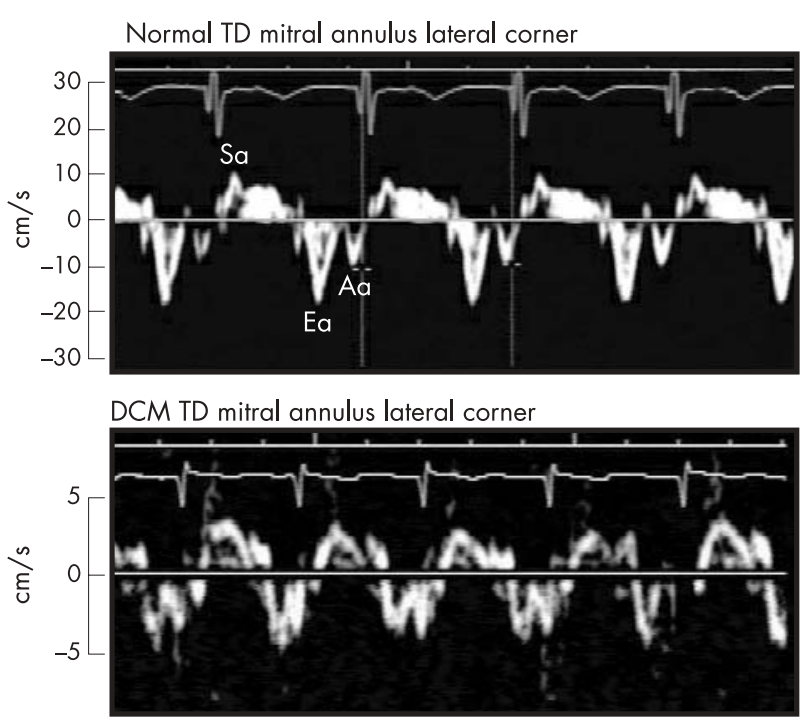

Figure 1 Tissue Doppler (TD) at the lateral mitral annulus corner in a patient with dilated cardiomyopathy (DCM) (lower panel) compared with a control group participant (upper panel). Note the greatly diminished systolic $(\mathrm{Sa})(4 \mathrm{~cm} / \mathrm{s})$ and early diastolic $(\mathrm{Ea})$ velocities $(5 \mathrm{~cm} / \mathrm{s})$ in the child with DCM compared with $10 \mathrm{~cm} / \mathrm{s}$ and $18 \mathrm{~cm} / \mathrm{s}$ in the healthy child.

management of congestive heart failure at some stage, with 22 patients requiring administration of intravenous inotropic support (dopamine $\geqslant 5 \mu \mathrm{g} / \mathrm{kg} / \mathrm{min}$, milrinone $0.25 \mu \mathrm{g} / \mathrm{kg}$ / min, or both). Seven patients underwent orthotopic heart transplantation and three patients died of congestive cardiac failure during the study period. Thirty patients met the PEP.

\section{Echocardiographic findings in DCM patients versus controls}

Children with DCM had dilated left ventricles, with thicker left ventricular posterior walls, lower LVEF, and higher Tei indices than the control group (table 1). Mitral Doppler inflow patterns showed equivalent $\mathrm{E}$ wave inflow velocity, A wave inflow velocity, and mitral $\mathrm{E}$ wave acceleration times between the groups. The isovolumetric contraction and relaxation times were longer in the DCM group than in normal controls, and the mitral deceleration time was shorter in the DCM group than in controls. RVFAC overall was significantly abnormal in the DCM group, with a mean of $31 \%$ compared with $61 \%$ for the normal controls. There was a significant reduction in TD velocities in children with DCM compared with controls (fig 1) except for the tricuspid lateral wall systolic velocity (table 1).

\section{Predictors of PEP}

The median age at presentation was slightly older in those who reached the PEP (table 2). Variables significantly predictive of the PEP on univariate analysis were LVEF, right ventricular Tei index (fig 2), and tricuspid Ea velocity (table 3). LVEF and tricuspid Ea velocity were predictive of the PEP on multivariate analysis but not left or right ventricular Tei indices (table 3). Tricuspid Ea velocity $<8.5 \mathrm{~cm} / \mathrm{s}$ had $87 \%$ specificity and $60 \%$ sensitivity for patients reaching the PEP. An LVEF $<30 \%$ had a $68 \%$ specificity and $74 \%$ sensitivity for patients reaching the PEP. Combining an LVEF $<30 \%$ and tricuspid Ea $<11.5 \mathrm{~cm} / \mathrm{s}$ had $100 \%$ specificity and $44 \%$ sensitivity for patients reaching the PEP.

\section{Predictors of death or transplantation}

There was a weak association between mitral Ea, Aa, or Sa velocities and adverse clinical outcomes (table 4). Tricuspid Ea velocity was significantly lower in patients who died or underwent transplantation (figs 3 and 4) than in those who were alive $(p=0.03)$. Although the tricuspid Sa velocity was not significant it trended towards significance in predicting need for transplantation or death as an outcome $(p=0.09)$. LVEF and RVFAC were both significantly reduced in children who died or required transplantation $(\mathrm{p}=0.01$ and $\mathrm{p}=0.02$, respectively $)$.

\section{Prediction of hospitalisation}

The mitral lateral Ea, tricuspid Ea, and septal Ea velocities were predictive of patients requiring hospitalisation, with each velocity significantly reduced in these patients $(\mathrm{p}<0.05$ for each) (table 5$)$. The LVEF $(\mathrm{p}<0.001)$ but not the left ventricular Tei index $(p=0.16)$ was significantly lower in patients needing hospitalisation for congestive heart failure.

\begin{tabular}{|c|c|c|c|}
\hline Variable & PEP reached $(n=30)$ & PEP not reached $(n=24)$ & $\mathrm{p}$ Value \\
\hline \multicolumn{4}{|l|}{ Demographics } \\
\hline Age (years) & $5.1(2.0-13.7)$ & $3.7(1.3-8.1)$ & 0.78 \\
\hline \multicolumn{4}{|l|}{ Ventricular dimensions } \\
\hline LVEDD $\mathrm{z}$ score & $3.72(2.29)$ & $2.71(0.30)$ & 0.13 \\
\hline LVPW z score & $-0.33(-0.63)$ & $0.55(1.84)$ & 0.24 \\
\hline \multicolumn{4}{|l|}{ TR and ventricular function } \\
\hline TR jet velocity $(\mathrm{m} / \mathrm{s})$ & $2.8(0.4)$ & $2.6(0.3)$ & 0.25 \\
\hline LV Tei index & $0.63(0.20)$ & $0.48(0.14)$ & 0.09 \\
\hline RV Tei index & $0.60(0.11)$ & $0.44(0.11)$ & $<0.001$ \\
\hline $\operatorname{LVEF}(\%)$ & $22(9-32)$ & $36(24-48)$ & $<0.001$ \\
\hline RVFAC (\%) & $30(9)$ & $34(9)$ & 0.06 \\
\hline \multicolumn{4}{|l|}{ TD measurements } \\
\hline Mitral lateral Ea $(\mathrm{cm} / \mathrm{s})$ & $10.6(3.8)$ & $13.5(4.8)$ & 0.02 \\
\hline Mitral lateral $\mathrm{Aa}(\mathrm{cm} / \mathrm{s})$ & $5.4(2.1)$ & $5.1(1.7)$ & 0.98 \\
\hline Mitral lateral Sa $(\mathrm{cm} / \mathrm{s})$ & $6.2(4.7-8.5)$ & $7.3(5.6-8.3)$ & 0.30 \\
\hline Mitral septal Ea $(\mathrm{cm} / \mathrm{s})$ & $6.8(6.2-8.3)$ & $10.2(7.5-12.1)$ & 0.002 \\
\hline Mitral septal Aa $(\mathrm{cm} / \mathrm{s})$ & $4.3(3.6-6.8)$ & $6.3(4.9-7.5)$ & 0.03 \\
\hline Mitral septal Sa $(\mathrm{cm} / \mathrm{s})$ & $4.5(3.9-5.8)$ & $6.0(5.1-7.9)$ & 0.003 \\
\hline Tricuspid lateral $\mathrm{Ea}, \mathrm{cm} / \mathrm{s}$ & $11.5(4.7)$ & $13.8(3.8)$ & 0.04 \\
\hline Tricuspid lateral Aa $(\mathrm{cm} / \mathrm{s})$ & $8.3(2.5)$ & $9.3(2.6)$ & 0.17 \\
\hline Tricuspid lateral $\mathrm{Sa}(\mathrm{cm} / \mathrm{s})$ & $10.2(7.8-11.7)$ & $11.5(9.2-13.5)$ & 0.15 \\
\hline
\end{tabular}



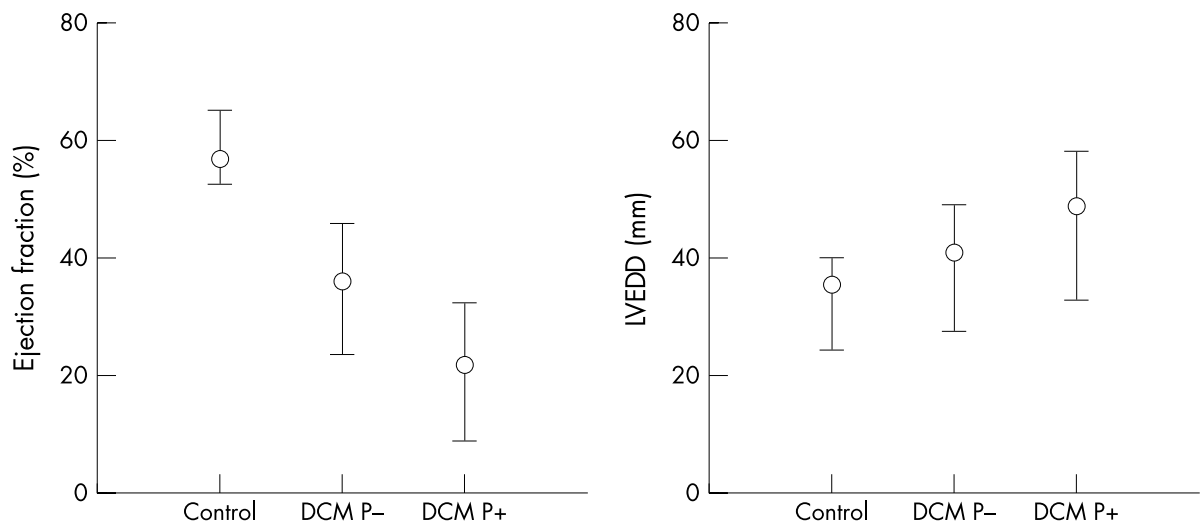

Figure 2 Comparison of mean (SD) of left ventricular ejection fraction (LVEF), left ventricular end diastolic dimension (LVEDD), left ventricular posterior wall (LVPW) z score, and left ventricular Tei index for controls and patients who did $(\mathrm{P}+)$ and did not reach the primary end point $(\mathrm{P}-)$. $\mathrm{p}$ Value $<0.05$ between controls and patients with DCM for each variable.
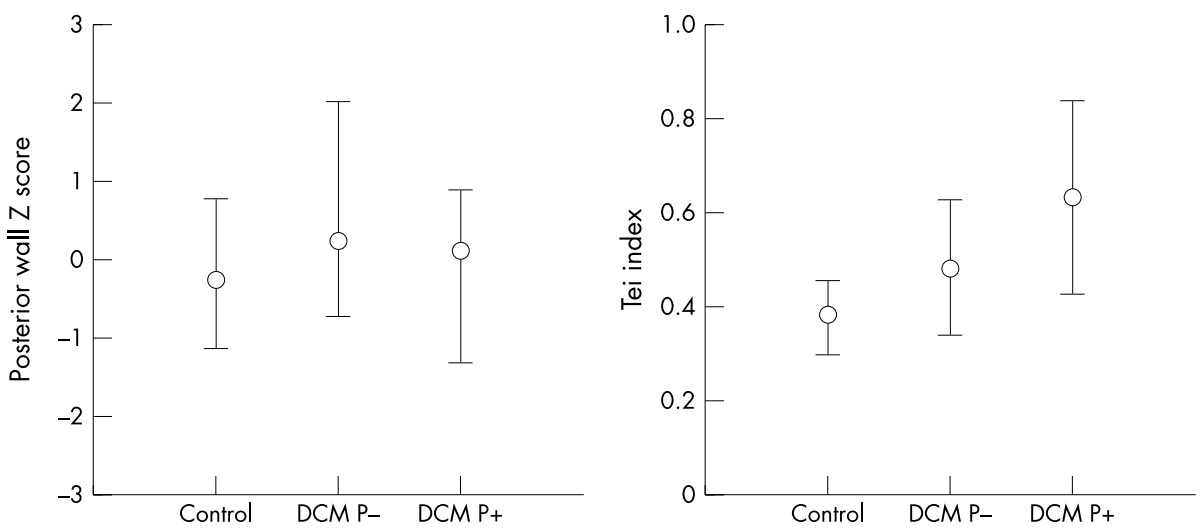

Predictors of use of intravenous inotropic support There were significant differences in the mitral, tricuspid, and septal velocities in the 22 patients who were treated with intravenous inotropic support (dopamine with or without milrinone) during hospital admission and those who did not receive inotropic treatment (table 6 ). The mitral lateral Ea $(\mathrm{p}<0.001)$ (fig 5), septal Ea $(\mathrm{p}<0.001)$, and tricuspid Ea velocities $(p=0.02)$ were greatly decreased in those requiring inotropic support. The Aa velocities for the respective areas were also significantly decreased but to a lesser extent than the Ea velocities. LVEF, RVFAC, and right ventricular Tei index $(\mathrm{p}<0.05)$ were significantly lower in children who were treated with intravenous inotropic treatment; the left ventricular Tei index was not significantly different $(\mathrm{p}=0.22)$.

\section{DISCUSSION}

Predictors of adverse clinical outcomes among children with DCM remain incompletely defined. ${ }^{1-5}$ Previous studies have reported reduced LVEF, decreased posterior wall thickness, cardiomegaly, presence of arrhythmia, and lack of improvement in ventricular function with administration of therapeutic agents as adverse prognostic factors. ${ }^{2-5} 2728$ A large retrospective study showed by multivariate analysis that young age at presentation was associated with improved survival and by univariate analysis that the presence of mural thrombus, left ventricular end diastolic pressure $>20 \mathrm{~mm} \mathrm{Hg}$, and age of presentation after 2 years of age were associated with poor prognosis. ${ }^{1}$ With the rapid introduction in recent years of ventricular assistance devices and the successful use of cardiac transplantation, identification of a more sensitive, reproducible, and preferably noninvasive index of poor outcome in children with DCM remains important to allow early stratification of children into groups with poor prognosis. Such risk stratification should optimise medical treatment and identify patients who require close surveillance. Although LVEF has been the primary echocardiographic variable in assessing ventricular function in patients with DCM, the left ventricle may be so dilated as to make measuring LVEF accurately impossible (nine of 70 study patients in this cohort). TD imaging, which has not previously been investigated as a prognostic factor in DCM in children, appears to be a useful measure to identify poor outcome in association with other more commonly used measures of cardiac function.

\section{Left ventricular dimensions}

LVEDD was larger in patients with DCM than in the control group. LVEDD was increased in patients who reached the PEP compared with those who did not, although the difference was not significant. Results of previous studies have been equivocal over the prognostic value of posterior left ventricular wall thickness. ${ }^{2}$ In our study children with DCM had thicker ventricles than did the control group but, interestingly, those with a thicker posterior wall were less likely to reach the PEP, corroborating prior reports that thicker left ventricular posterior wall is associated with a better prognosis. ${ }^{2}$ It has been proposed that patients with thicker ventricles have greater muscle mass, reduced wall stress, and therefore a propensity to improve. Alternatively a thicker wall may result from a local inflammatory process with the potential for recovery of ventricular function after inflammatory quiescence in children with myocarditis. ${ }^{2}$

\section{Right ventricular dimensions}

Two dimensional echocardiography showed abnormal right ventricular systolic function in children with DCM with significantly reduced RVFAC. This abnormality in right ventricular function may result from the myopathic process involving the right heart or may be secondary to dysfunctional septal motion from an increased left ventricular end diastolic pressure. A previous study evaluating 31 children 


\begin{tabular}{|c|c|c|c|}
\hline Variable & Odds ratio & $5 \%-95 \% \mathrm{Cl}$ & $\mathrm{p}$ Value \\
\hline \multicolumn{4}{|l|}{ Multivariate analysis } \\
\hline Tricuspid Ea velocity & 0.683 & 0.509 to 0.917 & 0.011 \\
\hline LVEF & 0.833 & 0.736 to 0.944 & 0.004 \\
\hline \multicolumn{4}{|l|}{ Univariate analysis } \\
\hline Tricuspid Ea velocity & 0.708 & 0.578 to 0.868 & $<0.001$ \\
\hline RV Tei index & 1.073 & 1.002 to 1.149 & 0.04 \\
\hline LVEF & 0.895 & 0.839 to 0.956 & $<0.001$ \\
\hline
\end{tabular}

\begin{tabular}{|c|c|c|c|}
\hline Variable & Death or transplantation $(n=9)$ & Alive $(n=45)$ & $\mathrm{p}$ Value \\
\hline \multicolumn{4}{|l|}{ Mitral inflow } \\
\hline Peak E velocity $(\mathrm{cm} / \mathrm{s})$ & $85(20)$ & $82(14)$ & 0.65 \\
\hline Peak $A$ velocity $(\mathrm{cm} / \mathrm{s})$ & $52(22)$ & $50(21)$ & 0.77 \\
\hline Acceleration time (ms) & $68(15)$ & 77 (17) & 0.25 \\
\hline Deceleration time (ms) & $105(41)$ & $118(32)$ & 0.21 \\
\hline \multicolumn{4}{|l|}{ Ventricular function } \\
\hline LV Tei index & $0.73(0.19)$ & $0.55(0.18)$ & 0.06 \\
\hline RV Tei index & $0.61(0.13)$ & $0.51(0.13)$ & 0.08 \\
\hline LVEF (\%) & $14(6)$ & $35(13)$ & 0.01 \\
\hline RVFAC (\%) & $26(10)$ & $34(7)$ & 0.02 \\
\hline \multicolumn{4}{|l|}{ TD measurements } \\
\hline Mitral lateral Ea $(\mathrm{cm} / \mathrm{s})$ & $9.1(5)$ & $12.0(4)$ & 0.09 \\
\hline Mitral lateral Aa $(\mathrm{cm} / \mathrm{s})$ & $5.1(2.4)$ & $5.5(1.8)$ & 0.65 \\
\hline Mitral lateral Sa $(\mathrm{cm} / \mathrm{s})$ & $5.3(3.4-6.6)$ & $6.8(5.0-8.6)$ & 0.07 \\
\hline Mitral septal Ea $(\mathrm{cm} / \mathrm{s})$ & $7.7(5.4-8.4)$ & $8.1(6.3-10.4)$ & 0.37 \\
\hline Mitral septal Aa $(\mathrm{cm} / \mathrm{s})$ & $5.3(4.3-7.7)$ & $5.6(3.9-7.0)$ & 0.52 \\
\hline Mitral septal Sa $(\mathrm{cm} / \mathrm{s})$ & $5.4(2.0)$ & $5.8(2.4)$ & 0.46 \\
\hline Tricuspid lateral Ea $(\mathrm{cm} / \mathrm{s})$ & $9.3(3.7)$ & $12.7(3.9)$ & 0.03 \\
\hline Tricuspid lateral Aa $(\mathrm{cm} / \mathrm{s})$ & $8.4(2.5)$ & $8.7(2.7)$ & 0.75 \\
\hline Tricuspid lateral $\mathrm{Sa}(\mathrm{cm} / \mathrm{s})$ & $8.3(7.2-10.7)$ & $11.0(8.8-13.4)$ & 0.09 \\
\hline
\end{tabular}

with DCM and restrictive cardiomyopathy supports this observation, reporting that patients with lower right ventricular systolic pressures and higher ejection fractions have improved survival. ${ }^{29}$ Similarly an adult study has reported that higher right heart ejection fraction is associated with better short term survival. ${ }^{29} 30$

\section{Two dimensional echocardiographic variables, mitral inflow, and Tei index}

As expected, compared with the control group, children with DCM have larger left ventricles, lower LVEF, and higher Tei indices. Left ventricular isovolumetric contraction and relaxation times were significantly prolonged in children with DCM compared with controls, although this did not differentiate children with DCM who reached the PEP. Transmitral Doppler inflow velocities were equivalent between groups, as were acceleration times, but there was a significant reduction in the mitral $\mathrm{E}$ wave deceleration time in children with DCM. Similar adult studies have shown that decreased mitral E wave deceleration time correlates with NYHA classification and by univariate analysis is also a predictor of adverse clinical outcome, in addition to Tei index and LVEF. ${ }^{31}$

In prior adult studies the Tei index has had a variable significance for patients with cardiomyopathy and in some studies it had no predictive power. ${ }^{31-34}$ The Tei index is a potentially attractive index of global ventricular function, as it is independent of heart rate and is easily and reliably obtained. ${ }^{31}$ In our study cohort, although the left ventricular Tei index was significantly higher in children with DCM than in the control group (table 1), it was a relatively weak predictor of death or transplantation $(p=0.06)$, need for hospitalisation ( $\mathrm{p}=0.16)$, or the use of inotropic
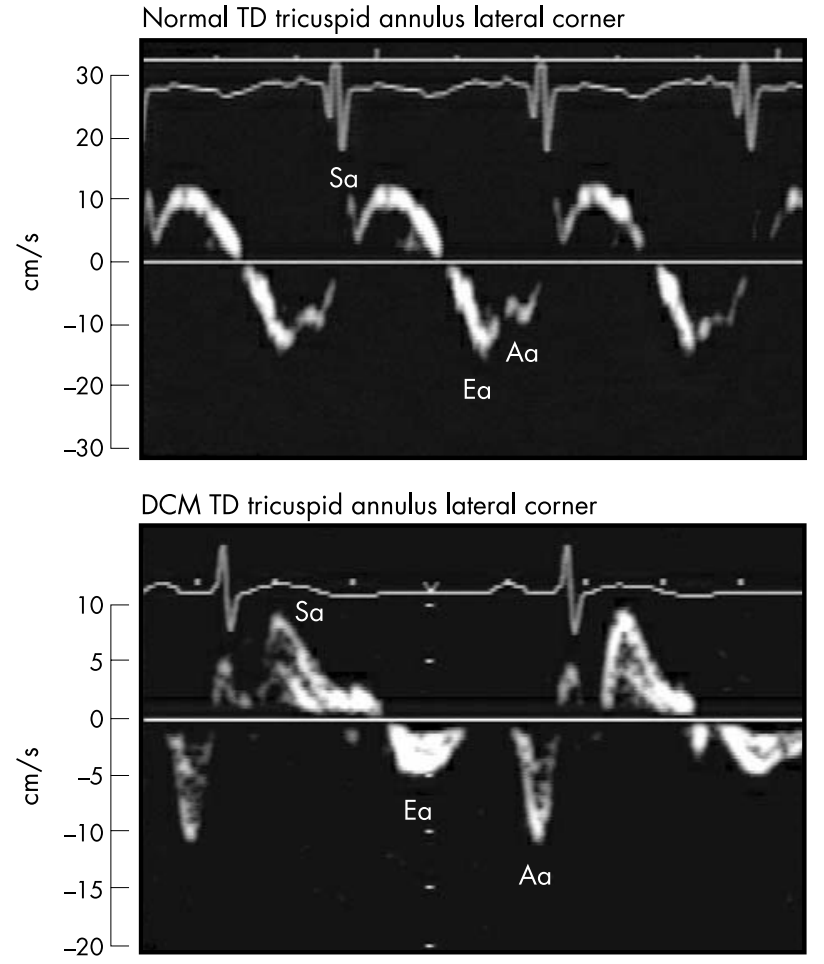

Figure 3 TD at the lateral tricuspid annulus in a patient who subsequently required transplantation (lower panel) compared with a normal control participant (upper panel). Note the significantly diminished tricuspid Ea velocity measuring $5 \mathrm{~cm} / \mathrm{s}$ in the patient requiring transplantation. There is partial fusion of the $\mathrm{Ea}(16 \mathrm{~cm} / \mathrm{s})$ and Aa velocity in the normal control participant. 


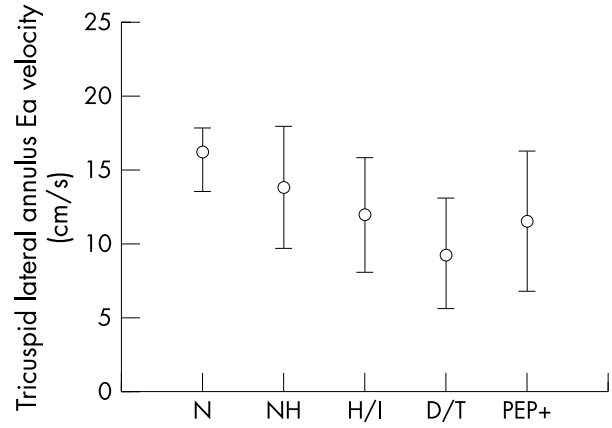

Figure 4 Comparison of mean (SD) tricuspid Ea velocities in normal control group $(N)$, patients not hospitalised $(N H)$, patients requiring inotropes $(H / I)$, patients who died or underwent transplantation $(D / T)$, and patients reaching the primary end point $(\mathrm{PEP}+)$.

support $(\mathrm{p}=0.22)$. The right ventricular Tei index was also a weak predictor of clinical outcomes by multivariate analysis (table 3 ). The tricuspid regurgitation jet was measurable in only 16 patients and did not differentiate those reaching the PEP. Of note, the LVEF but not the LVEDD was a predictor of meeting the PEP by multivariate analysis.

\section{TD as predictor of adverse clinical outcomes}

We have shown that TD velocities are significantly reduced at the mitral and tricuspid annuli in children with DCM compared with age and sex matched controls. More importantly, TD velocities allowed discrimination between patients with DCM who reached the PEP - that is, required hospitalisation or transplantation-and those at risk of death. Although there were significant differences in systolic velocities between the groups, early diastolic velocities at the mitral lateral, mitral septal, and tricuspid lateral walls were most significantly different between groups, indicating that diastolic dysfunction is an important component associated with clinical deterioration. ${ }^{28}$

Significant differences in tricuspid annular early diastolic TD velocities, right ventricular Tei index, and RVFAC by conventional two dimensional echocardiography strongly implicate right ventricular dysfunction as an important predictor of adverse outcome in DCM. Several reasons may account for reduced early diastolic velocities in the right ventricular free wall in such patients. Although the basilar right ventricular free wall motion is influenced by left ventricular and septal wall contractility in addition to right
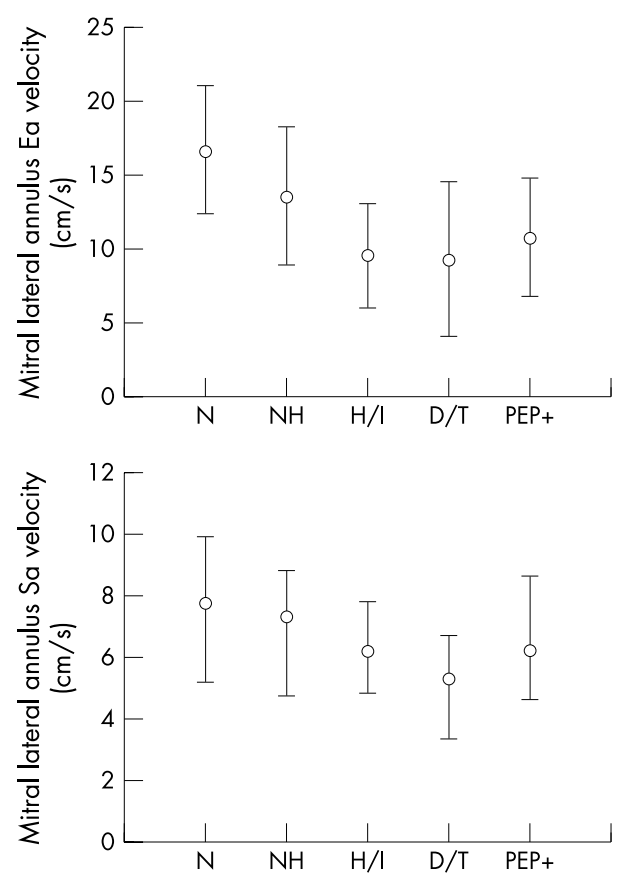

Figure 5 Comparison of median (25-75th centile) for mitral lateral annulus Ea and Sa velocities between patient groups.

atrial contraction, asynchronous activation of the right ventricle may cause abnormal right ventricular diastolic relaxation. This may be a potentially treatable pathophysiology and may be a surrogate marker for pacing protocols; interestingly, one recent adult study obtained significant improvement in cycle efficiency (ratio of the area of acquired pressure dimension loop to that of the ideal loop for that segment) with right ventricular pacing in comparison with left ventricular or biventricular pacing in patients with dilated poorly contracting left ventricle. ${ }^{35}$ Other potential causes of reduced right ventricular diastolic velocities may be increased subendocardial wall stress, ischaemic changes, or architectural changes in myocyte fibril arrangement. ${ }^{36}$ Right ventricular dysfunction may also reflect increased left ventricular end diastolic pressure, which secondary to a severely dilated left ventricle may impair normal right ventricular diastolic relaxation. In our study, the tricuspid early diastolic velocity was significantly lower in the transplantation/death group than those who survived; previous studies have also reported that right ventricular

\begin{tabular}{|c|c|c|c|}
\hline Variable & Hospitalised $(n=30)$ & Not hospitalised $(n=24)$ & $p$ Value \\
\hline \multicolumn{4}{|l|}{ Ventricular function } \\
\hline LV Tei index & $0.54(0.44-0.79)$ & $0.43(0.41-0.68)$ & 0.16 \\
\hline RV Tei index & $0.61(0.13)$ & $0.51(0.13)$ & 0.08 \\
\hline LVEF (\%) & $26(15-34)$ & $38(34-39)$ & $<0.001$ \\
\hline RVFAC (\%) & $30(9)$ & $34(10)$ & 0.06 \\
\hline \multicolumn{4}{|l|}{ TD measurements } \\
\hline Mitral lateral Ea $(\mathrm{cm} / \mathrm{s})$ & $10.6(3.9)$ & $13.4(4.5)$ & 0.02 \\
\hline Mitral lateral $\mathrm{Aa}(\mathrm{cm} / \mathrm{s})$ & $5.3(2.2)$ & $5.6(1.4)$ & 0.55 \\
\hline Mitral lateral $\mathrm{Sa}(\mathrm{cm} / \mathrm{s})$ & $6.2(4.9-8.1)$ & $7.3(4.8-8.7)$ & 0.67 \\
\hline Mitral septal Ea $(\mathrm{cm} / \mathrm{s})$ & $7.5(6.2-9.2)$ & $9.4(7.3-11.9)$ & 0.05 \\
\hline Mitral septal $\mathrm{Aa}(\mathrm{cm} / \mathrm{s})$ & $4.5(3.8-6.8)$ & $6.2(4.4-7.4)$ & 0.17 \\
\hline Mitral septal Sa $(\mathrm{cm} / \mathrm{s})$ & $5.1(4.1-6.8)$ & $5.4(4.7-7.7)$ & 0.14 \\
\hline Tricuspid lateral Ea $(\mathrm{cm} / \mathrm{s})$ & $11.2(3.9)$ & $13.8(4.1)$ & 0.04 \\
\hline Tricuspid lateral Aa $(\mathrm{cm} / \mathrm{s})$ & $8.7(2.7)$ & $9.9(2.5)$ & 0.13 \\
\hline Tricuspid lateral $\mathrm{Sa}(\mathrm{cm} / \mathrm{s})$ & $10.9(8.2-12.8)$ & $11.6(9.4-14.6)$ & 0.37 \\
\hline
\end{tabular}




\begin{tabular}{|c|c|c|c|}
\hline \multicolumn{4}{|l|}{$\begin{array}{l}\text { Table } 6 \\
\text { DCM }\end{array}$} \\
\hline Variable & $\begin{array}{l}\text { Inotropic support } \\
(n=22)\end{array}$ & $\begin{array}{l}\text { No inotropic support } \\
(\mathrm{n}=32)\end{array}$ & $p$ Value \\
\hline \multicolumn{4}{|l|}{ Ventricular function } \\
\hline LV Tei index & $0.56(0.43-0.86)$ & $0.45(0.41-0.61)$ & 0.22 \\
\hline RV Tei index & $0.60(0.11)$ & $0.43(0.11)$ & $<0.05$ \\
\hline LVEF (\%) & $21(15-32)$ & $38(33-39)$ & $<0.001$ \\
\hline RVFAC (\%) & $32(23-37)$ & $36(32-41)$ & 0.01 \\
\hline \multicolumn{4}{|l|}{ TD measurements } \\
\hline Mitral lateral Ea $(\mathrm{cm} / \mathrm{s})$ & $9.4(3.3)$ & $14.0(4.2)$ & $<0.001$ \\
\hline Mitral lateral Aa $(\mathrm{cm} / \mathrm{s})$ & $4.6(1.7)$ & $6.2(1.8)$ & 0.001 \\
\hline Mitral lateral Sa $(\mathrm{cm} / \mathrm{s})$ & $6.2(4.9-7.7)$ & $7.3(5.2-8.9)$ & 0.33 \\
\hline Mitral septal Ea $(\mathrm{cm} / \mathrm{s})$ & $6.7(6.1-7.9)$ & $10.1(7.5-12.1)$ & $<0.001$ \\
\hline Mitral septal $\mathrm{Aa}(\mathrm{cm} / \mathrm{s})$ & $4.3(3.6-6.0)$ & $6.5(4.2-7.5)$ & 0.02 \\
\hline Mitral septal Sa $(\mathrm{cm} / \mathrm{s})$ & $4.9(4.0-6.0)$ & $5.4(4.6-7.7)$ & 0.09 \\
\hline Tricuspid lateral Ea $(\mathrm{cm} / \mathrm{s})$ & $11.9(3.8)$ & $14.2(4.1)$ & 0.02 \\
\hline Tricuspid lateral $\mathrm{Aa}(\mathrm{cm} / \mathrm{s})$ & $8.5(2.6)$ & $10(2.4)$ & 0.03 \\
\hline Tricuspid lateral $\mathrm{Sa}(\mathrm{cm} / \mathrm{s})$ & $10.3(7.9-12.5)$ & $11.6(9.4-14.6)$ & 0.10 \\
\hline
\end{tabular}

dysfunction is an important risk factor in overall mortality and morbidity. ${ }^{29}$ Conceivably, children may sustain adequate cardiac output with significantly reduced left ventricular contractility, but ventricular "cross talk" with concomitant right ventricular systolic and diastolic function may portend a significant increase in morbidity and mortality.

\section{Study limitations}

The sensitivity of TD (tricuspid early diastolic velocity) alone was limited in predicting the PEP and, despite a relatively high specificity, this may limit its use in assessing clinical outcomes in children with DCM. Sixteen patients, $22 \%$ of the total study cohort, were excluded from the study because of suboptimal two dimensional imaging $(\mathrm{n}=3)$, inability to obtain accurate LVEF determination $(\mathrm{n}=9)$, or poor quality of TD profiles $(n=4)$. Poor TD profiles may also limit the clinical application of TD. TD velocities have well recognised limitations including tethering and translation effects, which may also limit their clinical use. Precise perpendicular interrogation of the myocardium is essential, which may not be feasible in all patients because of geometric changes in the ventricles. Two dimensional left ventricular dimensions were measured to be consistent between patients. Nine patients entered the study late, after commencement of medicines, which may have affected their TD velocities.

\section{Conclusions}

Children with DCM have significantly lower TD velocities than an age and sex matched control group. Left ventricular dimensions are limited in predicting risk of adverse clinical events among patients. Significantly reduced LVEF is more sensitive but less specific than reduced tricuspid early diastolic velocities in predicting adverse clinical outcomes. Further studies are required on the role of $\mathrm{TD}$ and to determine other more sensitive non-invasive indices of ventricular dysfunction for identifying children with DCM at risk of adverse clinical outcomes.

\section{ACKNOWLEDGEMENTS}

We are grateful to the cardiac ultrasonographers at Texas Children's Hospital for their assistance in this project, particularly Jin Wu, Heather Schoenig, and Joseph Lawley. We are grateful to Mr Lance Patterson for his generous computer assistance and Joe Martinez for generating the graphs. Dr McMahon was generously supported in this project by funding from the Abercrombie Section of Pediatric Cardiology, Texas Children's Hospital.

\section{Authors' affiliations}

C J McMahon, W J Dreyer, I Finkelshtyn, X Cao, B W Eidem, L I Bezold, S W Denfield, J A Towbin, R H Pignatelli, Lillie Frank Abercrombie Department of Pediatric Cardiology, Texas Children's Hospital and Baylor College of Medicine, Houston, Texas, USA

S F Nagueh, Department of Cardiology, Methodist Hospital, Baylor College of Medicine, Houston, Texas, USA

R S Eapen, Department of Pediatric Cardiology, University at Southwestern Medical School, Dallas, Texas, USA

\section{REFERENCES}

1 Burch M, Siddiqi SA, Celermajer DS, et al. Dilated cardiomyopathy in children: determinants of outcome. Br Heart J 1994;72:246-50.

2 Carvalho JS, Silva CM, Shinebourne EA, et al. Prognostic value of posterior wall thickness in childhood dilated cardiomyopathy and myocarditis. Eur Heart J 1996;17:1233-8.

3 Lewis AB. Prognostic value of echocardiography in children with idiopathic dilated cardiomyopathy. Am Heart J 1994;128:133-6.

4 Ciszewski A, Bilinska ZT, Lubiszewska B, et al. Dilated cardiomyopathy in children: clinical course and prognosis. Pediatr Cardiol 1994;15:121-6.

5 Acar $\mathbf{P}$, Merlet $P$, Iserin L, et al. Impaired cardiac adrenergic innervation assessed by MIBG imaging as a predictor of treatment response in childhood dilated cardiomyopathy. Heart 2001;85:692-6.

6 Rihal CS, Nishimura RA, Hatle LK, et al. Systolic and diastolic dysfunction in patients with clinical diagnosis of dilated cardiomyopathy: relation to symptoms and prognosis. Circulation 1994;90:2772-9.

7 Dagdeviren B, Akdemir O, Eren M, et al. Prognostic implication of myocardial texture analysis in idiopathic dilated cardiomyopathy. Eur J Heart Fail 2002;4:41-8.

8 Mahon NG, Hedman AE, Padula M, et al. Fractal correlation properties of R-R interval dynamics in asymptomatic relatives of patients with dilated cardiomyopathy. Eur J Heart Failure 2002;4:151-8.

9 Yi G, Goldman JH, Keeling P, et al. Heart rate variability in idiopathic dilated cardiomyopathy: relation to disease severity and prognosis. Heart 1997;77:108-14.

10 Dini FL, Cortigiani L, Baldini U, et al. Prognostic value of left atrial enlargement in patients with idiopathic dilated cardiomyopathy and ischemic cardiomyopathy. Am J Cardiol 2002;89:518-23.

11 Hansen A, Haass M, Zugek C, et al. Prognostic value of Doppler echocardiographic mitral inflow patterns: implications for risk stratification in patients with chronic congestive heart failure. J Am Coll Cardiol 2001;37:1049-55.

12 Naqvi TZ, Goel RK, Forrester JS, et al. Usefulness of left ventricular mass in predicting recovery of left ventricular systolic function in patients with symptomatic idiopathic dilated cardiomyopathy. Am J Cardiol 2000;85:624-9.

13 Grimm W, Hoffmann J, Menz V, et al. Prediction of major arrhythmic events and sudden cardiac death in dilated cardiomyopathy. The Marzburg cardiomyopathy study design and description of baseline clinical characteristics. Herz 2000;25:189-99.

14 Nagueh SF, Bachinski LL, Meyer D, et al. Tissue Doppler consistently detects myocardial abnormalities in patients with hypertrophic cardiomyopathy and provides a novel means for an early diagnosis before and independent of hypertrophy. Circulation 2001;104:128-30.

15 Shan K, Bick RJ, Poindexter BJ, et al. Relation of tissue Doppler derived myocardial velocities to myocardial structure and beta-adrenergic receptor density in humans. J Am Coll Cardiol 2000;36:891-6. 
16 Nagueh SF, Lakkis NM, Middleton KJ, et al. Doppler estimation of left ventricular filling pressures in patients with hypertrophic cardiomyopathy. Circulation 1999;99:254-61.

17 Nagueh SF, Mikati I, Kopelen HA, et al. Doppler estimation of left ventricular filling pressure in sinus tachycardia: a new application of tissue Doppler imaging. Circulation 1998;98:1644-50.

18 Nagueh SF, Middleton KJ, Kopelen HA, et al. Doppler tissue imaging: a noninvasive technique for evaluation of left ventricular relaxation and estimation of filling pressures. J Am Coll Cardiol 1997;30:1527-33.

19 Nagueh SF, Kopelen HA, Lim DS, et al. Tissue Doppler imaging consistently detects myocardial contraction and relaxation abnormalities, irrespective of cardiac hypertrophy, in a transgenic rabbit model of human hypertrophic cardiomyopathy. Circulation 2000;102:1346-50.

20 Weidemann F, Eyskens B, Sutherland GR. New ultrasound methods to quantify regional myocardial function in children with heart disease. Pediatr Cardiol 2002;23:292-306.

21 Mori K, Hayabuchi Y, Kuroda Y, et al. Left ventricular wall motion abnormalities in healthy children measured by pulsed wave Doppler tissue echocardiography: normal values and relation to age and heart rate. J Am Soc Echocardiogr 2000;13:1002-11.

22 Kapusta L, Thijssen JM, Cuypers MH, et al. Assessment of myocardial velocities in healthy children using tissue Doppler imaging. Ultrasound Med Biol 2000;26:229-37.

23 Mercier JC, DiSessa TG, Jarmakani JM, et al. Two-dimensional echocardiographic assessment of left ventricular volumes and ejection fraction in children. Circulation 1982;65:962-9.

24 Vitarelli A, Sciomer S, Ferro Luzzi M, et al. Estimation of right atrial volume and function by an online echocardiographic edge detection system. Echocardiography 1998;15:527-36.

25 Harada K, Tamura M, Toyono M, et al. Comparison of right ventricular Tei index by tissue Doppler imaging to that obtained by pulse Doppler in children without heart disease. Am J Cardiol 2002;90:566-9.
26 Mori Y, Rice MJ, McDonald RW, et al. Evaluation of systolic and diastolic ventricular performance of the right ventricle in fetuses with ductal constriction using the Doppler Tei index. Am J Cardiol 2001;88:1173-8.

27 Schmaltz AA, Apitz J, Hort W. Dilated cardiomyopathy in childhood: problems of diagnosis and long-term follow-up. Eur Heart $J$ 1987;8:100-5

28 Chen SC, Nouri S, Balfour I, et al. Clinical profile of congestive cardiomyopathy in children. J Am Coll Cardiol 1990;15:189-93.

29 Nield LE, McCrindle BW, Bohn DJ, et al. Outcomes for children with cardiomyopathy awaiting transplantation. Cardiol Young 2000;10:358-66

30 Gavazzi A, Berzuini C, Campana C, et al. Value of right ventricular ejection fraction in predicting short-term prognosis of patients with severe chronic heart failure. J Heart Lung Transplant 1997; 16:774-85.

31 Dujardin KS, Tei C, Yeo T, et al. Prognostic value of a Doppler index combining systolic and diastolic performance in idiopathic-dilated cardiomyopathy. Am J Cardiol 1998;82:1071-6.

32 Koyama J, Ray-Sequin PA, Falk RH. Prognostic significance of ultrasound myocardial tissue characterization in patients with cardiac amyloidosis. Circulation 2002;106:556-61.

33 Tei C, Dujardin KS, Hodge DO, et al. Doppler index combining systolic and diastolic myocardial performance: clinical value in cardiac amyloidosis. J Am Coll Cardiol 1996;28:658-664.

34 Tei C, Dujardin KS, Hodge DO, et al. Doppler echocardiographic index for assessment of global right ventricular function. J Am Soc Echocardiogr 1996;9:838-47.

35 Varma C, O'Callaghan P, Mahon NG, et al. Effect of multisite pacing on ventricular coordination. Heart 2002;87:322-8.

36 Opie LH. Heart failure and neurohumeral responses. Heart failure today. The heart. Physiology from cell to circulation. Philadelphia: Lipincott-Raven Publishers, 1997:475-511.

\section{IMAGES IN CARDIOLOGY}

\section{Saccular dilatations originating from the conus artery}

A 58 year old man was admitted with a complaint of chest pain upon exertion during the previous 10 days, which was increasing in duration and intensity. The patient was hospitalised with a diagnosis of unstable angina. At electrocardiography, ST-T changes were observed in DII, DIII, and aVF. The patient's blood pressure was $130 / 85 \mathrm{~mm} \mathrm{Hg}$, pulse rate 76 beats/min, and systemic findings were normal. Antiischaemic treatment, which included aspirin, $\beta$ blocker, clopidogrel, heparin, statin, and angiotensin converting enzyme inhibitor, was initiated. During follow up, there was no increase in cardiac enzymes. The echocardiographic examination was normal. Following stabilisation with medical treatment, coronary angiography was performed. The left anterior descending artery and circumflex artery were completely normal. In the right coronary artery (RCA), consecutive non-significant lesions in the mid segment and severe stenosis on the posterior descending artery bifurcation in the RCA at the left anterior oblique position were determined. Slow contrast progression was observed in the region of the conus artery at the same position (panel A). In the right anterior oblique position, contrast caused by saccular dilatations originating from conus artery was detected (panel B), which decreased immediately (panel C) and virtually disappeared 10 minutes (panel D) after the catheter was withdrawn. A stent was implanted to resolve the severe stenotic lesion, and the patient was discharged after arrangements were made for medical treatment.

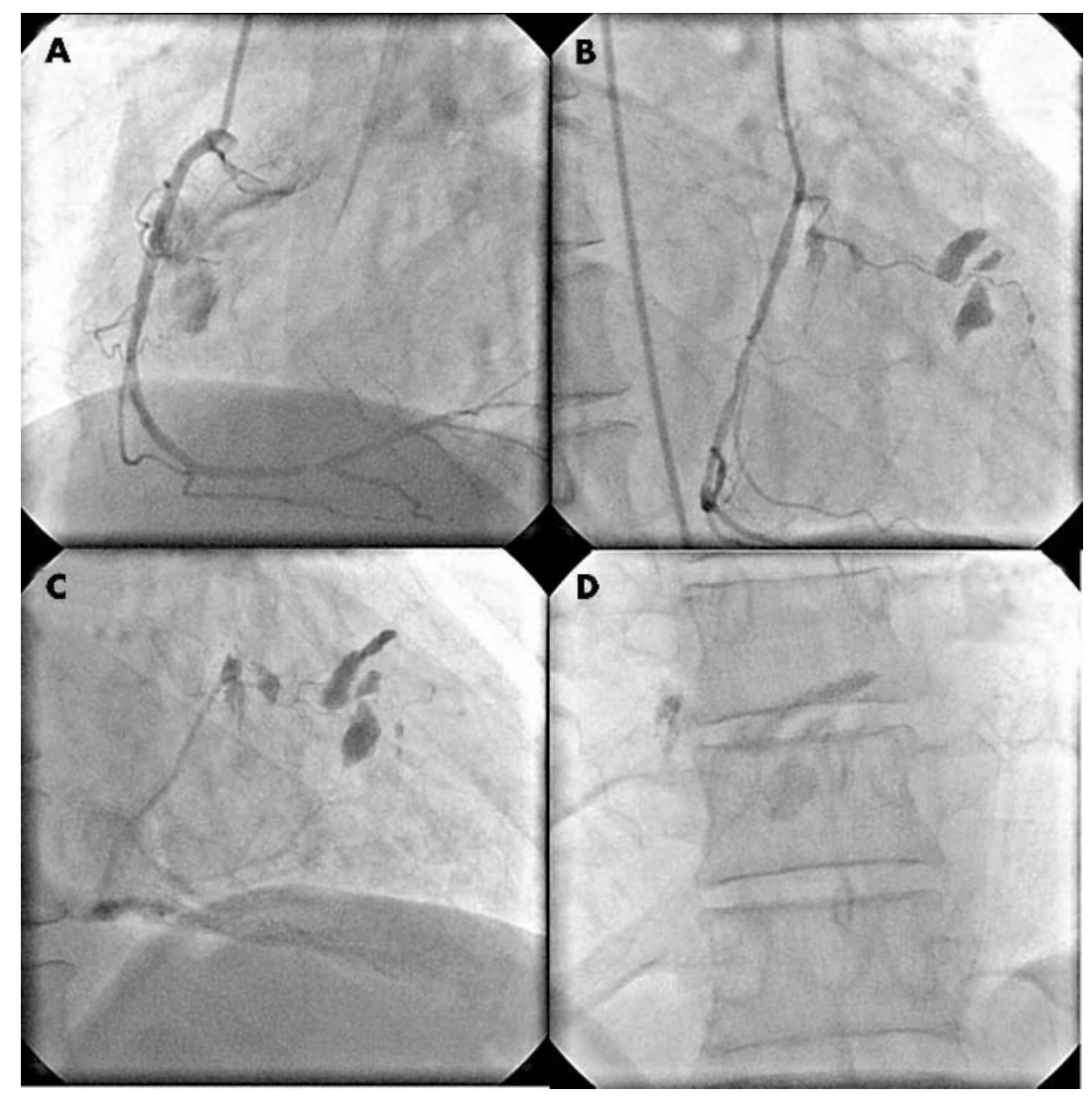

M Yazici

$S$ Demircan 